Asian J. Med. Biol. Res. 2018, 4 (1), 141-148; doi: 10.3329/ajmbr.v4i1.36833

\author{
Asian Journal of \\ Medical and Biological Research \\ ISSN 2411-4472 (Print) 2412-5571 (Online) \\ www.ebupress.com/journal/ajmbr
}

\title{
Article \\ Study on the vaccination and medication program in commercial broiler farming at farmer's level
}

\author{
MR Islam Ratan ${ }^{1}$, MH Ali ${ }^{1}$, Most. Sumona Akter ${ }^{3}$, SM Bulbul ${ }^{1}$, Md. Shawkat Ali ${ }^{1}, \mathrm{~N} \mathrm{Sakib}^{3}$, S Sarker ${ }^{3}$ and \\ Md.Yousuf $\mathrm{Ali}^{2} *$ \\ ${ }^{1}$ Bangladesh Agricultural University, Mymensingh-2202, Bangladesh \\ ${ }^{2}$ Bangladesh Livestock Research Institute, Regional Station, Baghabari, Sirajgonj - 6770, Bangladesh \\ ${ }^{3}$ Department of Livestock Services, Farmgate, Dhaka-1341, Bangladesh
}

*Corresponding author: Md. Yousuf Ali, Bangladesh Livestock Research Institute, Regional Station, Baghabari, Shahjadpur, Sirajgonj, Bangladesh. E-mail: 113yousuf.bau@gmail.com, myousuf@blri.gov.bd

Received: 07 March 2018/Accepted: 21 March 2018/ Published: 29 March 2018

\begin{abstract}
The Geographic area of this study was 5 selected unions of Kalihati upazila in Tangail district. A total number of 50 broiler farmers were interviewed to conduct the study. The objective of the study was to know the current vaccination and medication status in the study area. The information that collected from the respondents were age, education, main occupation, family members, training, annual income, number of broiler in each batch, name of broiler strain, mortality rate, vaccination practicing rate, current situation of antibiotic and growth promoter use, use of footbath, use of disinfectant for spraying in inside and outside of the farm, percentage of antibiotic and feed withdraw rate before marketing of broiler, source of vaccine and medicine at farmer level, consultants of the farmers for vaccine and medicine specially antibiotic use, vaccination and medication cost in a batch. Commonly used vaccine and medicine list with their company name were also collected from the study area market. A correlation table was prepared to determine the relationship among some variables; education Vs age, education Vs income, income Vs no of broiler in a batch, education Vs antibiotic withdraw, income Vs antibiotic withdraw. Significant negative correlations $(p<0.01)$ was found only with age Vs education and other all variables were positively and significantly correlated. The problems related to present vaccination and medication service and their probable solution suggested by broiler farmers were also focused in this study.
\end{abstract}

Keywords: vaccination; medication; withdraw; strain; antibiotics

\section{Introduction}

The poultry sub-sector is an important avenue in fostering agricultural growth and reduce malnutrition for the people in Bangladesh. Poultry contributes about 22 to 27 percent of the total animal protein supply in the country (Prabakaran et al., 2003). This sub-sector has proved as an attractive economic activity, thereby, indicating its`importance for the entire economy. The sector accounts for 14 percent of the total value of livestock output and is growing rapidly (Raihan and Mahmud et al., 2008). During 1970-80, the poultry population growth rate was 0.7 percent which increased to 4 percent per year during 1990-2005 (Begum et al., 2008). The current market size is $\$ 1$ billion with about 150,000 small and medium enterprises. The sector employs nearly 5 million people directly or indirectly (The Poultry Site.com, 2007). Bangladesh is a country of serious malnutrition where about 48 per cent of the population lives below the poverty line (Bangladesh Bureau of Statistics 1998). The per capita consumption of animal protein in Bangladesh is only $11.8 \mathrm{~g}$ per day (Bangladesh Bureau of Statistics 2001) whereas the standard requirement of $36 \mathrm{~g}$ is recommended by UNO (Islam and Ahmed et al., 1985). The broiler industry is considered an important avenue to reduce poverty and malnutrition as well as unemployment problems of Bangladesh. Although commercial poultry started in 1980, 
until now only14\% of the meat comes from commercial farming systems (Alam et al., 1995). For this reason, broiler farming has been playing a key role in providing meat to overcome the malnutrition and serve as a tool for employment generation and poverty alleviation (Raha et al., 2007). Poultry vaccines are widely applied to prevent and control contagious poultry diseases. Their use in poultry production is aimed at avoiding or minimizing the emergence of clinical disease at farm level, thus increasing production. Vaccines and vaccination programs vary broadly in regard to several local factors (e.g. type of production, local pattern of disease, costs and potential losses) and are generally managed by the poultry industry. In the last decade, the financial losses caused by the major epidemic diseases of poultry (avian influenza and Newcastle disease) have been enormous for both the commercial and the public sectors. Thus, vaccination should also be applied in the framework of poultry disease eradication programs at national or regional levels under the official supervision of public Veterinary Services. Administration of medicine to food-producing animals requires not only consideration of effects on the animal but also the effects on humans who ingest food from these animals. In short, after food-producing animals have been exposed to drugs in order to cure or prevent disease or to promote growth, the effects of the residues of such treatment may have on humans should be known. These residues consist of the parent compound or compounds derived from the parent drug (or both) including metabolites, and residues bound to macromolecules .Concern has been expressed about possible harmful effects on humans through the use of drugs, as follows: (1) increased microbial drug resistance, (2) drug residues in food, (3) allergic reactions and sensitization to antimicrobials, and (4) drug toxicity (BLACK, 1984). Within broiler industry, antibiotics are not only used to treat sick poultry, but also to promote faster growth and prevent disease in healthy. Feeding broiler on antibiotics leads to a build-up of bacteria that are antibiotic resistant. Antibiotic resistance in and around farms is in fact particularly rapid and vigorous. The broilers are given very low doses of antibiotics. Low amounts of antibiotics may be too little to kill all the bacteria, but just enough for the bacteria to survive, mature and develop resistance. Indeed, the bacteria in these farms tend to be multi-resistant to antibiotics. The use of antibiotics in animal production has already been severely restricted, and the European Union has recently banned the use of coccidiostats for poultry. Although vaccine and medicine are using smoothly in commercial broiler farm but there is no established information on vaccination and medication status and no study yet has been done on this issue in different areas of Bangladesh. Keeping all points in mind the study was designed to fulfill the following objectives:

a) to know the status of vaccination and medication program in broiler farming.

b) to understand the current scenario of medication program (especially antibiotic).

c) to observe the problem conformation with vaccination and medication service.

d) to know the present market status of vaccine and medicine.

\section{Materials and Methods}

Among several methods of data collection, survey method was preferred. The word "survey" refers to a method of study in which an overall picture of a given universe is obtained by a systematic collection of all available data on the subject. The Interview schedule is given in the appendix chapter.

\subsection{Selection of the study area}

Keeping the objectives of the research in mind, the present study was conducted at Kalihati upazila under Tangail district. The area was selected for good communication facilities and availability of broiler farms. No study of this type was conducted previously in this area.

\subsection{Selection of farmers; vaccine and medicine seller}

A total of 50 respondents who had broiler farms were chosen for collecting data to address the objectives. Beside this 20 vaccines and medicine seller were selected from the study area.

\subsection{Preparation of the interview schedule}

The interview schedule was prepared based on the objectives of the study. It contained both open and closed form questions. Most easy, simple and direct questions were used to obtain information. The structured interview scheduled was designed to collect information from the farmers on the uses of vaccine and medicine. A draft schedule was developed before preparing the final schedule. The schedule was developed in a simple manner to avoid misunderstanding and to get accurate answer. Eventually it was finalized according to the experience gathered in the preliminary field survey. 


\subsection{Collection of data}

Data were collected following the direct interviews and making personal visits. Before making actual interview, the objectives of the study were explained clearly to the respondents. Interviews were normally conducted in the market or in respondent's house during their leisure time. Excellent co operation and co-ordination was obtained from all the respondents during data collection. Secondary data were collected at different times from drug pharmacy, veterinary doctor, upazila livestock officer, BBS, journals, reports and various published articles.

\subsection{Compilation of data}

Following the completion of data collection, all interview schedules were compiled, coded, tabulated and analyzed based on the objectives of study. The collected data were first transferred to MS- Excel spread sheets and compiled to facilitate the needed tabulation.

\subsection{Statistical analysis of data}

Analysis was mainly done through tabular and graphical representations. Tabular technique was applied for the analysis of data using simple statistical tools like arithmetic mean, maximum, minimum, percentage, standard deviation and correlation matrix.

\section{Results and Discussion}

\subsection{Socio-economic background of the farmers}

In this study 50 respondents were interviewed to find out the socio economic condition. In this study major 6 characteristics of the respondents were selected to find out the socio economic condition of the farmers. The selected characteristics included main occupation, age, level of education, family members, annual income (BDT), and source of money. Number and percentage distribution of respondents according to their main occupation, and source of money are shown in Table 1 . Table 1 revealed that out of the 50 respondents the majority $(70.0 \%)$ of the respondents had main occupation as agriculture, $22 \%$ were related in the livestock business, $2 \%$ were in service (NGO or Government) and rests of the farmers were related to other occupation. In case of sources of money, $58 \%$ of the farmers run their broiler farming business by own money, $26 \%$ taken loan from bank, $16 \%$ from NGO loan.

\subsection{Distribution of broiler farmer according to family member}

The family comprises $2-4$ members were $42 \%$ that categorized into small, $48 \%$ were medium(5-7 members) and large size ( 8 to 10 members) family were $10 \%$. Most of the family size was medium (5-7) with a mean of 5.34 and a standard deviation of 1.61 (Table 2).

\subsection{Annual income (Tk.) among farmers}

Income of the respondents referred to the earning (Tk.) by them from farming ranged from Tk. 20000 to 60000 annually with mean of Tk. 34720 and standard deviation of 10982.435. Among the respondents 50\% had low income, $26 \%$ had medium income, $14 \%$ had high income and $10 \%$ had very high income.

\subsection{Factors associated with broiler farming}

The major factors associated with broiler farming are strain of broiler birds, training on broiler farming, size of farm and mortality of broilers. Among these strain of broiler and training on broiler farming situation are shown in Table 3. From the Table 3 it raveled that $90.0 \%$ of farmer's select Cobb500 and the rest were chosen Hubbard classic. Haque (2001) showed that, $80 \%$ farmers were rearing Cobb-500, 10\% Ross broiler, 6\% Hubbard and 4\% Starbro. Most of the classic farmers preferred Cobb-500 because of better performances as had been observed by (Rahman et al., 2002). The table also showed that only $18 \%$ farmers received training from local YTC, ULO office, and NGOs and rest $82 \%$ of them were not trained. (Jin et al. 1988) found that $45 \%$ farmers had training and about $55 \%$ did not have any training on layer farming. So, more opportunity for training and development of training program as well as facilities should be measured.

\subsection{Farm size}

The farm size was measured by number of broilers, which was classified into three groups; 1) small, 2) medium and 3) Large. Number of broiler per farm was 860 with standard deviation of 449.94 and the broiler number ranged from 500 to 2500 . The Table 4 revealed that $40 \%$ farms were small, $50 \%$ farms were medium and $10 \%$ farms were in large category. Perhaps the most of the farmers think that it was easy and affordable for them to manage a farm sized in medium category. 


\subsection{Mortality of Broiler}

Standard mortality of Cobb-500 strain is $2-4 \%$ (Cobb management guide). But in this study, mortality of broiler was at an average $3.72 \%$ with a standard deviation 0.88156 .

\subsection{Some common features identified among the broiler farmers about vaccination in the study area}

\subsubsection{Practicing vaccination}

Almost all of the broiler farmers in the study area adopt proper vaccination. Among the visited farm, $98 \%$ farms practiced proper vaccination and the rest of the $2 \%$ farmer practiced vaccination improperly.

\subsubsection{Idea about sound vaccination program}

Among the 50 farmers, $80 \%$ farmer had idea about sound vaccination program. Rest of the $20 \%$ farmers didn't have idea about sound vaccination.

\subsubsection{Essentiality of vaccination}

In visited area, $98 \%$ farmer thought that vaccination is essential for their farming and another $2 \%$ farmers said that vaccination is not essential.

\subsection{Some common features identified among the broiler farmers about medication in the study area}

\subsubsection{Idea about residual effect of antibiotic}

In the study area $42 \%$ respondent had a brief idea about residual effect of antibiotic and rest $52 \%$ respondent had no any idea about residual effect of antibiotic in the human body.

\subsubsection{Use of footbath}

In the surveyed farms $12 \%$ farmer used footbath with different types of disinfectants and majority portion farmers that means rest $88 \%$ did not use footbath as bio-security measures. The present findings revealed that farmers followed guideline of WHO partially by using footbath in front of the gates and doors.

\subsubsection{Use of disinfectant in inside farm and surroundings area}

In the study area $90 \%$ farmer used disinfectants for spraying in inside and as well as surroundings area of the farm .on the other hand rest $88 \%$ did not use for spraying in inside and surroundings area of the farm which is a also a measures of bio-security.

\subsubsection{Effectiveness of medicine after occurring disease}

Among the visited farm, $82 \%$ farm owner said that antibiotic and other medicine is not effective in a diseased flock and the rest of the $18 \%$ farmer said they got good result using medicine after outbreak of disease in their farm.

\subsection{Vaccine that use mostly in broiler farming at farmers level}

In farmer level, all of the farmers used only two vaccines. They practiced vaccination for Ranikhet and Gumboro disease. All of the farmers used same method for vaccine administration and their dose administration time and age of administration almost same. There are many NewCastle and Gumboro disease vaccine is selling in the market for Broiler farming at the visited area. .Most of the poultry farmers used almost same company's vaccine. A list of mostly used vaccine and their company name is shown in Table 5.

\subsection{Most used antibiotics and their dose practiced at farmer level}

In visited area most of the farmers used almost same types of antibiotic for treatment of their birds in their flock. Name of the antibiotics that used by most of the broiler farm and their dose that practiced at farmer level are shown in Table 6.

\subsection{Most used growth promoters and their dose practiced at farmer level}

Name of the growth promoters that used by most of the broiler farmer and their dose that practiced in surveyed area at farmer level are shown in Table 7.

\subsection{Source of vaccine and medicine of broiler farmer}

From the surveyed data it revealed that farmers got their vaccine and medicine from dealer, company agent and feed seller. 
3.13. Cost of vaccination and medication in each batch for 1000 broiler

Most of the respondent of the study reported that for rearing 500 broilers vaccination cost was $600-700$ tk and medication cost 5000-6000 tk (Table 8). The respondent who had 1000 birds in each batch said that vaccination and medication incurs 1200-1300 tk and 10000-12000 tk respectively to the total cost (Table 8).

\subsection{Withdraw of antibiotic before marketing}

In the surveyed area all of the farmers used antibiotic. Farmers used antibiotic indiscriminately. Most of the farmer did not have any idea about residual effect of antibiotic in human body. From the study it was shown that $90 \%$ farmer did not withdraw antibiotic on their flock and they used antibiotic even at the eve of marketing. On the other hand only $8 \%$ farmer stopped using antibiotic prior to marketing. This study revealed that only $2 \%$ farmer withdrew antibiotic before at least 7 days of marketing but they did not follow it regularly. The surveyed result is shown in Table 9.

Table 1. Distribution of farmers according to respondent's main occupation, family members, sources of money $(\mathbf{N}=50)$.

\begin{tabular}{llll}
\hline Parameters & Categories & No. of farmers & \% of farmers \\
\hline \multirow{3}{*}{ Main Occupation } & Agriculture & 35 & 70.0 \\
& Livestock Business & 11 & 22.0 \\
& Service (NGO/Govt.) & 2 & 4.0 \\
& Others & 2 & 4.0 \\
Sources of money & Own & 29 & 58.0 \\
& Bank loan & 13 & 26.0 \\
\hline
\end{tabular}

Table 2. Distribution of broiler farmer according to family member.

\begin{tabular}{|c|c|c|c|c|}
\hline Family members & No. of farmers & $\%$ of farmers & Mean & Mean \\
\hline $2-4$ (small) & 21 & 42.0 & & \\
\hline 5-7 (medium) & 24 & 48.0 & 5.34 & 1.61 \\
\hline 8-10 (large) & 5 & 10.0 & & \\
\hline
\end{tabular}

Table 3. Strain of broiler and training associated with broiler farming.

\begin{tabular}{llll}
\hline Parameters & Categories & No. of farmers & \% of farmers \\
\hline Strain of broiler & Cobb500 & 45 & 90.0 \\
& Hubbard & 5 & 10.0 \\
Training on broiler farming & Have & 9 & 18.0 \\
& Have not & 41 & 82.0 \\
\hline
\end{tabular}

Table 4. Categorization of broiler farm.

\begin{tabular}{|c|c|c|c|c|}
\hline \multirow[t]{2}{*}{ Category } & \multicolumn{2}{|c|}{ Broiler farmer } & \multirow[t]{2}{*}{ Mean } & \multirow[t]{2}{*}{ Standard deviation } \\
\hline & Number & $\%$ & & \\
\hline Small (100- 500) & 20 & 40.0 & & \\
\hline Medium (501-1000) & 25 & 50.0 & 860.0000 & 449.94 \\
\hline Large (1001-above) & 5 & 10.0 & & \\
\hline
\end{tabular}

\subsection{Problems of vaccination program}

Although many problems were identified in the study area on vaccination program but the most important problem faced by broiler farmer was reported to be the high price of vaccine. Approximately $72 \%$ of respondents reported high price of vaccine and $10 \%$ reported small farming problem to get vaccine .In study area lack of knowledge and training on vaccination (10\%) also a major problem. Other problems in study area were unavailability of vaccine (4\%) and failure of vaccine (4\%). 
Table 5. List of mostly used vaccine for Ranikhet and Gumboro disease in farm.

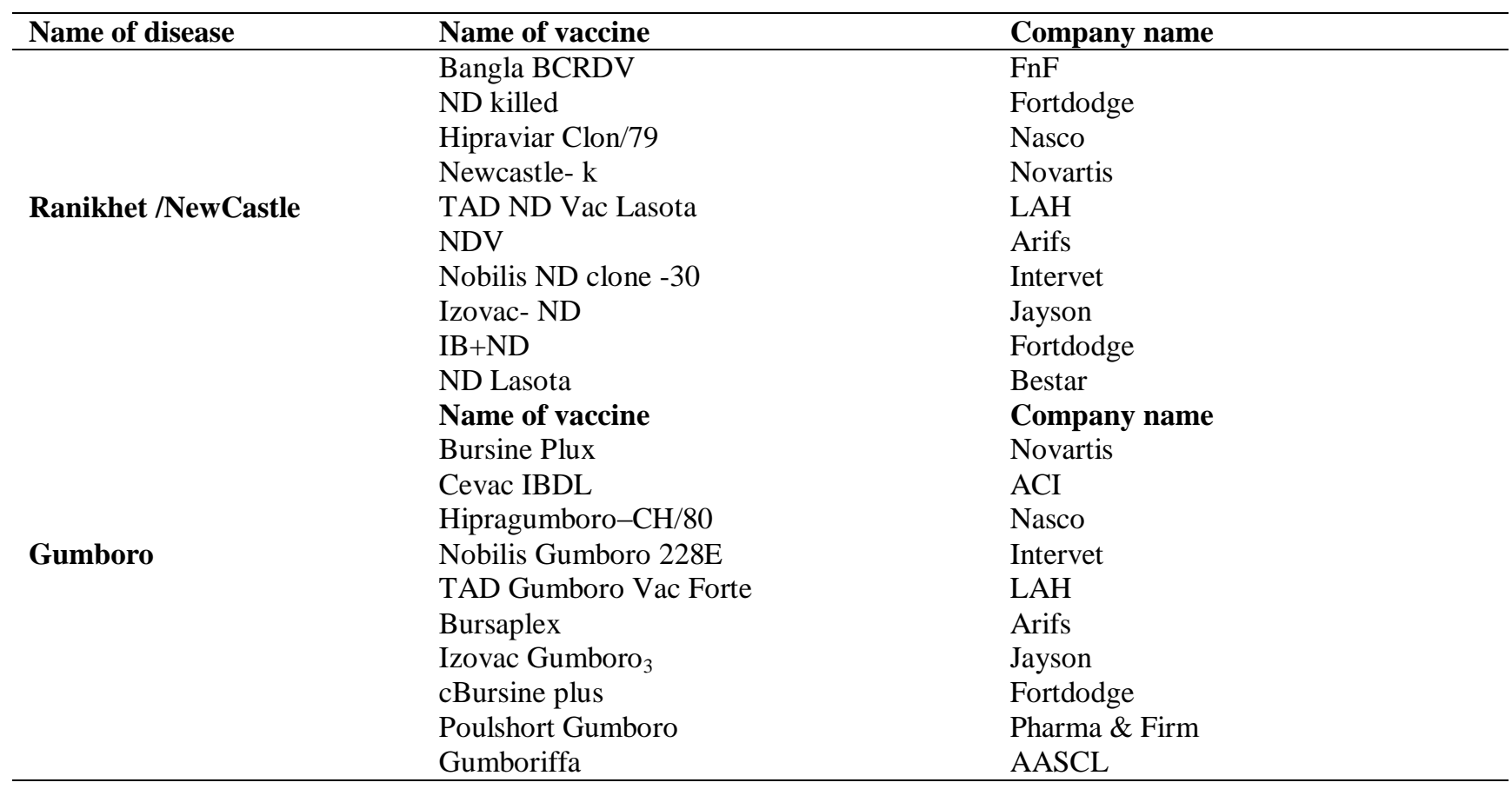

Table 6. List of antibiotics and their dose that practices commonly at farmer level.

\begin{tabular}{ll}
\hline Name & Dose \\
\hline Moxacil Vet & $1 \mathrm{gm} / \mathrm{L}$ drinking water for 3-5 days \\
Eromycin & $0.5 \mathrm{gm} / \mathrm{L}$ drinking water for $3-5$ days \\
Doxacil Vet & $1 \mathrm{gm} / 2 \mathrm{~L}$ drinking water for $3-5$ days \\
Enrocin & $1 \mathrm{ml} / \mathrm{L}$ drinking water for $3-5$ days \\
Renamycin & $1 \mathrm{gm} / 3 \mathrm{~L}$ drinking water for $3-7$ days \\
Miocol powder & $1 \mathrm{gm} / \mathrm{L}$ drinking water for 3-5 days \\
Tylosin-20 & $2.5 \mathrm{gm} / \mathrm{L}$ drinking water for $3-5$ days \\
Nava-cox & $2.5 \mathrm{gm} / \mathrm{L}$ drinking water for $3-5$ days \\
Sultrix powder & $1 \mathrm{gm} / \mathrm{L}$ drinking water for 3-5 days \\
Tiamul powder & $1 \mathrm{gm} / 3 \mathrm{~L}$ drinking water for 3-7 days \\
ESB & $2.5 \mathrm{gm} / \mathrm{L}$ drinking water for 3-5 days \\
Ampicoli & $1 \mathrm{gm} / \mathrm{L}$ drinking water for 3-5 days \\
Respiron & $1 \mathrm{ml} / \mathrm{L}$ drinking water for 3-5 days \\
Micro safe powder & $1 \mathrm{gm} / \mathrm{L}$ drinking water for 3-5 days \\
coxuril & $2.5 \mathrm{ml} / \mathrm{L}$ drinking water for 3-7 days \\
\hline
\end{tabular}

Table 7. List of growth promoters that uses commonly at farmer level.

\begin{tabular}{ll}
\hline Name & Dose \\
\hline Grow- up & $1 \mathrm{gm} / \mathrm{L}$ drinking water \\
Broiler boost & $1 \mathrm{gm} / \mathrm{L}$ drinking water \\
Maxigrow-P & $1 \mathrm{ml} / \mathrm{L}$ drinking water \\
Xtra-vit WS & $1 \mathrm{gm} / 5 \mathrm{~L}$ drinking water \\
Rena- WS & $1 \mathrm{gm} / 3 \mathrm{~L}$ drinking water \\
Super chick & $1 \mathrm{gm} / \mathrm{L}$ drinking water \\
High power GP & $1 \mathrm{gm} / \mathrm{L}$ drinking water \\
Bio-chicks & $1 \mathrm{gm} / \mathrm{L}$ drinking water \\
Active growth & $1 \mathrm{gm} / \mathrm{L}$ drinking water \\
\hline
\end{tabular}


Table 8. Cost of vaccination and medication in each batch for 1000 broiler.

\begin{tabular}{lll}
\hline Cost item & Cost in Tk & \% of total cost \\
\hline Feed cost & 70000 & 62 \\
Chick cost & 25000 & 22 \\
Litter and other cost & 5000 & 4 \\
Vaccination cost & 1300 & 1 \\
Medication cost & 12000 & 11 \\
\hline
\end{tabular}

Table 9. Withdraw of antibiotic before marketing.

\begin{tabular}{lll}
\hline Subject & No. of farmers & \% of farmers \\
\hline At least before 7 days & 1 & 2 \\
Before less than 7 days & 4 & 8 \\
Not withdraw & 45 & 90 \\
\hline
\end{tabular}

\subsection{Problems of medication program}

Similarly many problems were identified on medication program but the most important problem faced by broiler farmer was high cost of medicine. Approximately $80 \%$ of respondents reported high cost of medicine and $10 \%$ reported lack of suggestion to use medicine. In study area unavailability of medicine (6\%) also a mentionable problem. Other problem in study area was storage problem of some medicine (4\%).

\section{Conclusions}

They suggested reducing vaccine price, make vaccine available/supply from government and provide training on vaccination and seeking suggestions from veterinarian/livestock officer. A detailed description of the suggestions showed that $72.0 \%$ respondents suggested that reduce vaccine price, $14 \%$ farmers suggested that make vaccine available/supply from government. About 10\% farmers suggested that more suggestion is needed from veterinarian/ livestock officer, $4 \%$ farmers suggested to provide training on vaccination. From the above results summarized in this section suggest that the farmers in study area practiced vaccination in broiler without any justification and/or recommendation by the appropriate expert. About $60 \%$ respondents suggested reducing medicine price, $20 \%$ farmers said that need suggestions from veterinarian/ livestock officer to use medicine especially antibiotic. About $10 \%$ farmers suggested that make medicine available/ Supply from government and another $10 \%$ suggested provide training on proper medication program. From the study area it was appeared that farmers used antibiotics in broiler rarely with recommendation by the appropriate expert. Farmers use antibiotic without any prescription. If they found that their birds are not having good growth, they suddenly decide to use antibiotics. Even if one or two birds become seek, then they add antibiotics in water for the whole flock.

\section{Acknowledgements}

Special thanks to the authority of BAU specially Department of Poultry Science for taking such initiative and all the related scientists of this work.

\section{Conflict of interest}

None to declare.

\section{References}

Alam J, 1995. Livestock resource in Bangladesh -Present status and future potential, University Press Limited, Dhaka.

Bangladesh Bureau of Statistics, 2001. Statistical Yearbooks., Statistics Division, Ministry of BBS, 2005. Statistical Yearbooks. Bangladesh. Bangladesh Bureau of Statistics, Statistics Division, Ministry of Planning, Government of the People's Republic of Bangladesh, Dhaka, Bangladesh.

Bangladesh Bureau of Statistics, 1998. Report on the household expenditure survey, 1995-96, Dhaka.

Begum IA, 2008. Prospects and potentialities of vertically integrated contract farming in Bangladesh, $\mathrm{PhD}$ thesis, Department of Agricultural Development Economics, Hokkaido University, Japan.

Haque, 2001. Noted difference in the digestive system in cage and floor-reared commercial egg-type pullets. Poult. Sci., 64: 1035-1037.

Islam W, KM Ahmed and MAM Malek, 1985. Hymenopterous parasites on insect pests of two stored pulses. Bangladesh Journal of Zoology, 13: 1982-83. 
Jin L and JV Craig, 1988. Some effects of cage and floor rearing on commercial White Leghorn pullets during growth and the first year on egg production. Poult. Sci., 67: 1400-1406.

Raha K, BM Peters, B Wang, N Yu, AM Wollacott, LM Westerhoff and KM Merz Jr, 2007. The role of quantum mechanics in structure-based drug design. Drug Discov. Today, 12: 725-731.

Prabakaran R, 2003. Good practices in Planning and management of integrated commercial poultry production in South Asia, FAO Animal production and health paper, 159, Food and Agriculture organization of the United nations, Rome, 2003.

Rahman and MO North, 2003. Influence of alternative housing systems on table egg quality. World's Poultry Science Association: 231-237.

Raihan S and N Mahmud, 2008. Trade and Poverty Linkages: A Case Study of the Poultry Industry in Bangladesh, Cuts Cite, Working Paper No. 6. 